\title{
Article \\ Characteristics of Airflow Reversal of Excavation Roadway after a Coal and Gas Outburst Accident
}

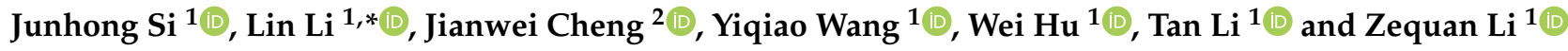 \\ 1 School of Emergency Technology and Management, North China Institute of Science and Technology, \\ Beijing 101601, China; sijunhong@ncist.edu.cn (J.S.); 201908522442wyq@ncist.edu.cn (Y.W.); \\ 202008570051hw@ncist.edu.cn (W.H.); 2020085700591t@ncist.edu.cn (T.L.); 201701257lzq@ncist.edu.cn (Z.L.) \\ 2 School of Safety Engineering, China University of Mining and Technology, Xuzhou 221008, China; \\ ChengJianwei@cumt.edu.cn \\ * Correspondence: 20190852246611@ncist.edu.cn
}

check for

updates

Citation: Si, J.; Li, L.; Cheng, J.;

Wang, Y.; Hu, W.; Li, T.; Li, Z.

Characteristics of Airflow Reversal of

Excavation Roadway after a Coal and

Gas Outburst Accident. Energies 2021,

14, 3645. https://doi.org/10.3390/

en14123645

Academic Editors: Sheng-Qi Yang,

Min Wang, Qi Wang, Wen Zhang,

Kun Du and Chun Zhu

Received: 17 May 2021

Accepted: 15 June 2021

Published: 18 June 2021

Publisher's Note: MDPI stays neutral with regard to jurisdictional claims in published maps and institutional affiliations.

\begin{abstract}
Determining the influence scope of the airflow disorder is an important problem after coal and gas outburst accidents in ventilation systems. This paper puts forward the indexes of airflow disorder, including the length of the excavation roadway, the outburst pressure, the pressure difference of the air door, and the air quantity of the auxiliary fan. Using the orthogonal table of L9 $\left(3^{4}\right)$ and numerical simulation method, the characteristics of airflow reversal are studied, and the outburst airflow reversal degree is calculated should the ventilation facility fail. Furthermore, on the basis of fuzzy comprehensive optimization theory, the comprehensive evaluation model of the airflow disorder is established. The results show that the length of the excavation roadway is the most important factor affecting the stability of the ventilation system, followed by the outburst pressure, pressure difference of the air door, and air quantity of the auxiliary fan. The influence of a gas outburst accident on the return air system is greater than that on the inlet air system, and a larger air velocity has a greater impact on the ventilation system, especially the air inlet part. Moreover, the airflow reversal degree of the ventilation system increases with the increase of the outburst pressure or decreases with the length of the excavation roadway. This paper provides a basis for the prevention of gas outburst accidents.
\end{abstract}

Keywords: airflow reversal; gas outburst; mine ventilation system; orthogonal experiment; numerical simulation

\section{Introduction}

A coal and gas outburst is an accident that is caused by a large amount of coal and gas being ejected into the underground roadway in a single moment [1]. In an outburst accident, the high-energy shock wave destroys the roadway facilities instantly and changes the roadway resistance and the structure of the ventilation network [2]. After the dynamic effect of the shock wave disappears, the gas continues to flow and diffuse unsteadily [3], generating ventilation pressure and additional force [4], causing airflow disorder [5], casualties, or secondary gas explosion accidents.

A coal and gas outburst is studied from three aspects: shock wave [6-8], outburst gas [9-12], and outburst coal rock [13,14]. The theoretical analysis [15] and numerical simulation are popular methods $[16,17]$ in a single roadway. After the outburst power disappears in the upwind roadway, Feng et al. [18] concluded, the influencing factors of the airflow reversal in the parallel branch include the pressure of the main fan, the height difference of roadway, the initial air velocity, length, and the sectional area of roadway. Yu et al. [19] pointed out that the airflow is affected by the seam inclination in the inlet roadway. However, the underground mine ventilation network is formed by connected roadways, and the study is often not limited to a single roadway. Zhou et al. [20] established $45^{\circ}$ and $135^{\circ}$ crossover tunnels to simulate the flow and attenuation rules of shock waves 
and gas in a gas outburst accident. The influence of air pressure increases with the increase of the angle between the excavation roadway and the adjacent excavation roadway, but the intersection of the roadway has no effect on the airflow reversal. They also found that the outburst pressure could not only lead to the airflow reversal in the downward ventilation roadway, but also may lead to the airflow reversal in parallel branches of the upward ventilation roadway [21,22]. The phenomenon of gas flow restriction and retention appears in the roadways with the air door and windshield, so draining the gas immediately is the key to prevent secondary disasters in the underground roadways.

In recent years, scholars have conducted a series of studies on the disaster process of the whole mine ventilation system during the outburst period. Due to the complexity of the ventilation system after an gas outburst accident, the tunneling face is usually seen as a unidirectional burst source, and a three-dimensional simulation method is adopted to simulate the flow process of air and gas in the ventilation system during the disaster period [23]. The result shows that the disturbance of the ventilation system is affected by the gas force, natural wind pressure, and ventilation power. Then, the characteristics of bidirectional gas outburst in the coal mining face are studied [24]. Different from the unidirectional outburst mode, the impact strength of this type is reduced. Ventilation facilities are the weak point of the ventilation system. The research mainly focuses on the characteristics of air door failure $[25,26]$, the reasonable position, the strength of the air door [27], as well as the automatic air door [28,29]. There is still a lack of research on the influencing factors of airflow disorders in ventilation systems when ventilation facilities fail. There are many factors that affect the ventilation system of a coal and gas outburst [30-32], it is particularly important to establish the index system of the airflow disorder and determine relatively important influencing factors when ventilation facilities fail, which could provide theoretical support for disaster prevention.

The whole paper is structured as follows: Section 2 introduces the ventilation system. In Section 3, the influencing factors of the airflow disorder induced by gas outburst accident are put forward. Using the orthogonal experiment analysis and numerical simulation method, the sensitivity factors of the airflow disorder when the ventilation facility fails are analyzed in Section 4. Section 5 conducts a comprehensive evaluation of the airflow disorder on the basis of fuzzy comprehensive optimization theory.

\section{Ventilation System and Its Simplification}

Most of the coal and gas outburst accidents occur in the heading face [24]. The ventilation system is formed by the excavation roadway, heading face, auxiliary fan, and air ducts. Figure 1 illustrates a forced ventilation system, which is the most commonly used ventilation form. It has the advantages of a small air leakage and large air supply. The fresh air is transported from the intake airway to the heading face through the auxiliary fan and air duct, and the polluted air enters the return airway through the excavation roadway. The air door obstructs fresh air and polluted air, and the air duct needs to pass through the air door. The blue arrow indicates the airflow direction of the fresh air, and the red one indicates the polluted air.

In general operation conditions, the order of the air gauge pressure is $\mathrm{P}_{20}>\mathrm{P}_{21}>\mathrm{P}_{22}$, $\mathrm{P}_{10}>\mathrm{P}_{11}>\mathrm{P}_{12}>\mathrm{P}_{13}, \mathrm{P}_{11}>\mathrm{P}_{31}>\mathrm{P}_{21}$.

According to graph theory, the air duct can be considered as a separate roadway for the air supply on the heading face, so it is an independent branch. There are nine branches and nine nodes in a general ventilation system. The ventilation system is simplified, as shown in Figure 2.

In a gas outburst accident, the air pressure of the roadway is redistributed as the gas concentration increases rapidly in the ventilation system, and the shock wave usually destroys the ventilation facilities. As a result, if the air door is invalid in a tunneling ventilation system, the outburst gas will flow into the intake airway. Then, the airflow will be reversed if the air pressure at the upwind side is lower than the outburst pressure. 


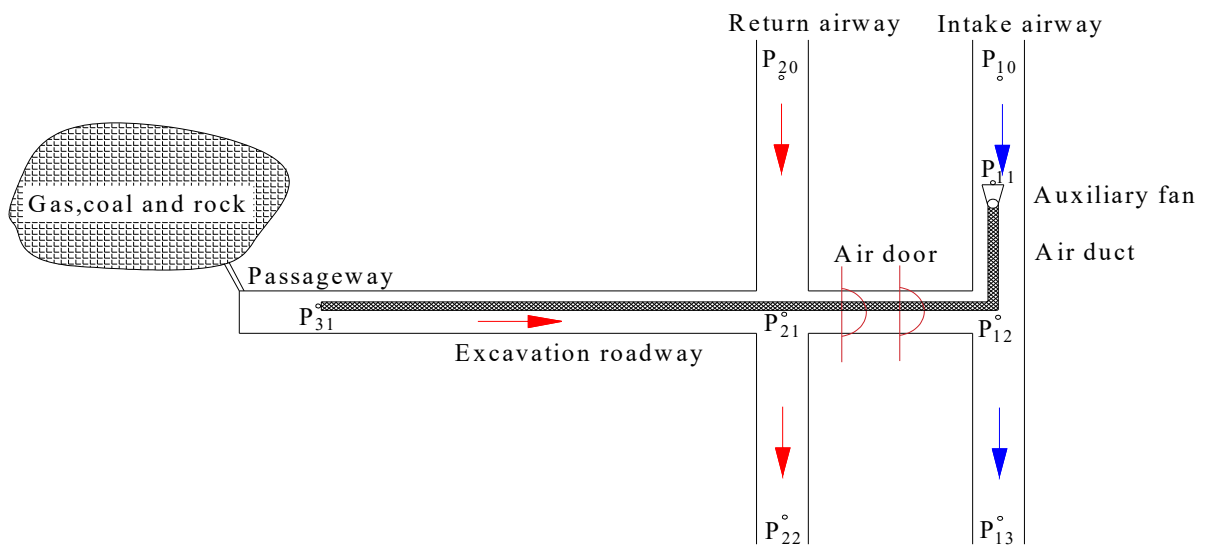

Figure 1. Sketch map of the ventilation system.

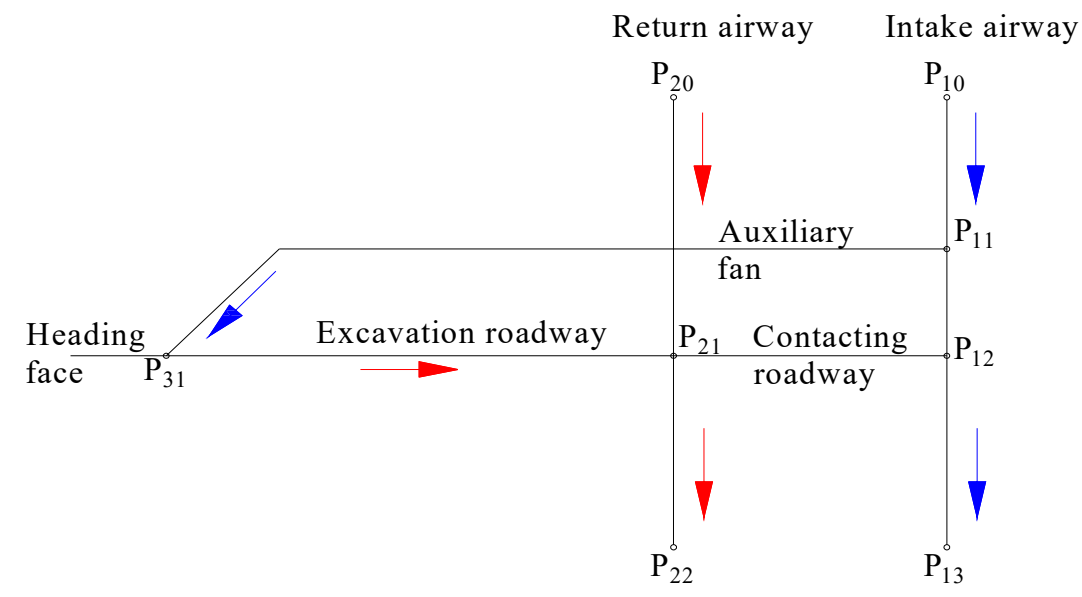

Figure 2. Diagram of the simplified ventilation network in a general ventilation system.

The outburst airflow reversal degree is defined as the influence of outburst gas on the airflow disorder in an airway, which is the ratio of the air quantity variation after the gas outburst accident and the original value. A positive reversal degree means that the airflow direction of the outburst gas is the same as the original airflow, and a negative reversal degree means that the airflow is reversed.

\section{Indexes of Airflow Disorder}

There are 3 factors that affect the safety and stability of the mine ventilation system, as shown in Figure 3.

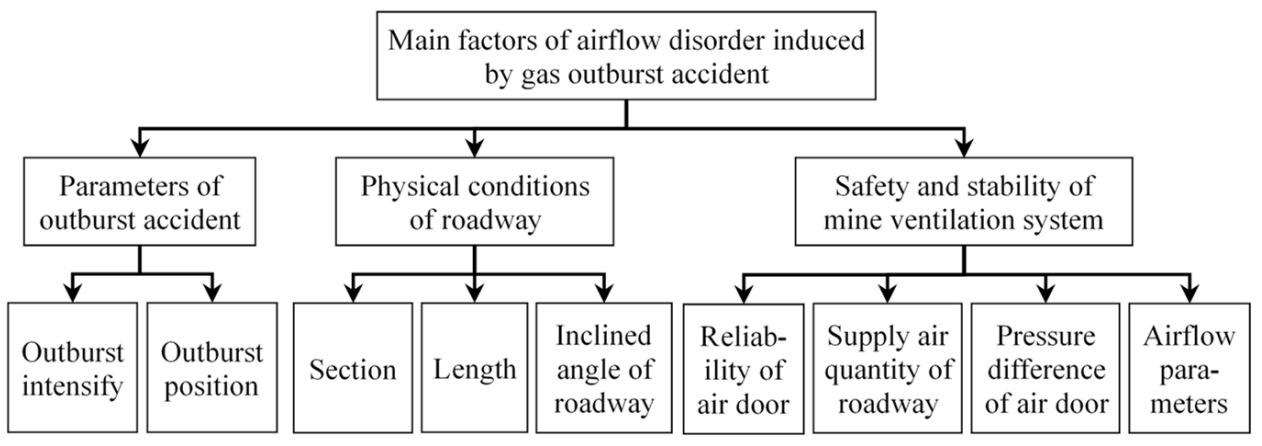

Figure 3. Hierarchical structure of factor indicators. 


\subsection{Parameters of Outburst Accident}

The outburst intensity indicates the amount of coal and rock thrown into the roadway and the amount of gas emissions in a coal and gas outburst accident. Because it is difficult to calculate the amount of gas emission, the outburst intensity is represented by the amount of outburst coal and rock. Usually, an outburst accident is divided into a small outburst accident $(<100 \mathrm{t})$, medium outburst accident $(<500 \mathrm{t})$, large outburst accident $(<1000 \mathrm{t})$, and extra-large outburst accident $(\geq 1000 \mathrm{t})$.

The outburst position refers to the place where the outburst accident occurs. If the air pressure of the outburst position is low, the outburst gas can be faster exhausted to the ground, as the outburst position is closer to the air shaft. On the contrary, it has a great impact on the ventilation system, especially the air intake roadway. Therefore, we can reduce the impact of the outburst accident on the ventilation system by reducing the air resistance of the return airway or increasing the intake airway.

\subsection{Physical Conditions of Roadway}

The characteristics of the roadway are determined by the physical conditions, including the section and length of roadway. Specifically, the outburst gas is easy to exhaust from the large section or the shorter length of roadway.

\subsection{Safety and Stability of Mine Ventilation System}

The high-pressure outburst gas suddenly flows into the roadway space in a gas outburst accident, which has a great impact on the mine ventilation system. It is easy to cause a large range of airflow disorders in the mine ventilation system after the shock wave destroys the air doors.

Among the above factors, the outburst pressure, length of roadway, pressure difference of the air door, and supply air quantity of the roadway are chosen to analyze the laws of the airflow disorder and the degree of influence in a mine ventilation system.

\section{Orthogonal Experiment}

\subsection{Orthogonal Design}

The orthogonal experiment is used for the analysis of the mutual influence of multiple factors [33]. Using the orthogonal table, an appropriate amount of representative points is selected from a large number of test points. Through the overall design, comprehensive comparison, and statistical analysis, the balanced sampling within the range of factor change is carried out. Then, the analysis of the representative results is achieved by a small number of tests.

In the orthogonal design, the table of $\mathrm{L}_{9}\left(3^{4}\right)$ is adopted to study the effect of 4 factors, i.e., $\mathrm{A}$ is the length of roadway, $\mathrm{B}$ is the outburst pressure, $\mathrm{C}$ is the pressure difference of air door, and $\mathrm{D}$ is the air quantity of the auxiliary fan on the airflow disorder in the mine ventilation system. The specific parameters of each test are illustrated in Table 1.

Table 1. Initial parameters of the orthogonal experiment.

\begin{tabular}{ccccc}
\hline Test Number & $\mathbf{A} / \mathbf{m}$ & $\mathbf{B} / \mathbf{M P a}$ & $\mathbf{C} / \mathbf{P a}$ & $\mathbf{D} / \mathbf{m}^{\mathbf{3}} \cdot \mathbf{m i n}^{-\mathbf{1}}$ \\
\hline $\mathrm{L}_{1}$ & 200 & 0.1 & 500 & 240 \\
$\mathrm{~L}_{2}$ & 200 & 0.2 & 1000 & 1200 \\
$\mathrm{~L}_{3}$ & 200 & 0.3 & 1500 & 600 \\
$\mathrm{~L}_{4}$ & 1000 & 0.2 & 1500 & 240 \\
$\mathrm{~L}_{5}$ & 1000 & 0.1 & 1000 & 600 \\
$\mathrm{~L}_{6}$ & 1000 & 0.3 & 500 & 1200 \\
$\mathrm{~L}_{7}$ & 2000 & 0.1 & 1500 & 1200 \\
$\mathrm{~L}_{8}$ & 2000 & 0.2 & 500 & 600 \\
$\mathrm{~L}_{9}$ & 2000 & 0.3 & 1000 & 240 \\
\hline
\end{tabular}


From Table 1, the level of each factor is in the common value range, such that the length of roadway is $200 \mathrm{~m}, 1000 \mathrm{~m}$, and $2000 \mathrm{~m}$, the outburst pressure is $0.1 \mathrm{MPa}, 0.2 \mathrm{MPa}$, and $0.3 \mathrm{MPa}$ respectively, the pressure difference of the air door is $500 \mathrm{~Pa}, 1000 \mathrm{~Pa}$, and $1500 \mathrm{~Pa}$, the air quantity of the auxiliary fan is $240 \mathrm{~m}^{3} / \mathrm{min}, 600 \mathrm{~m}^{3} / \mathrm{min}$, and $1200 \mathrm{~m}^{3} / \mathrm{min}$. A total of nine combined schemes are designed.

\subsection{Mathematical Experiment Modeling}

\subsubsection{Physical Model and Meshing}

According to the orthogonal tests, it is necessary to establish three physical models with different roadway lengths. The spatial relationship model and grid meshing of the ventilation system are shown in Figure 4. The parameters of each test model are shown in Table 2.

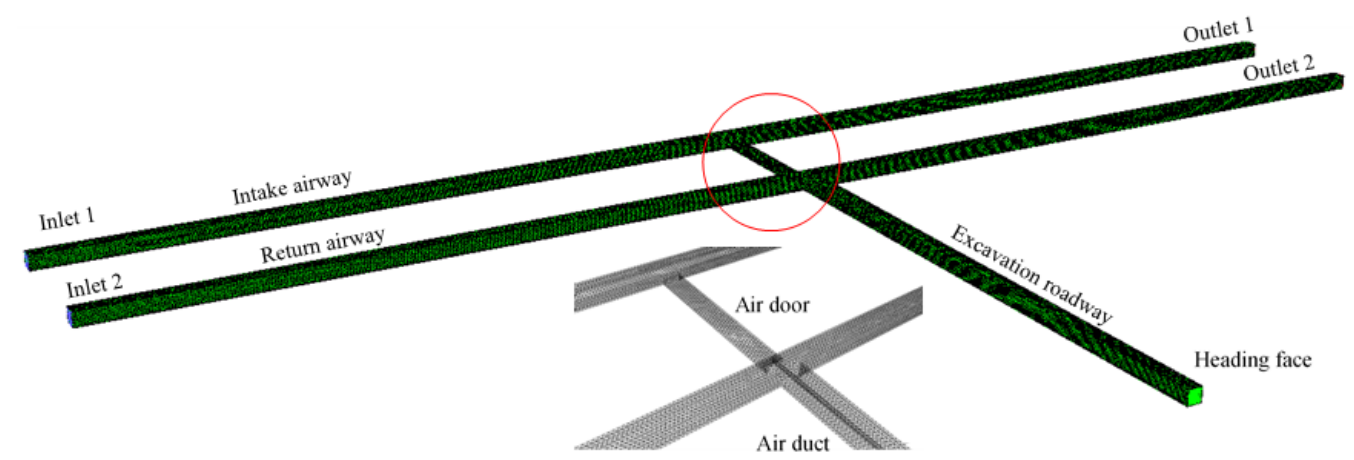

Figure 4. Physical model and its meshing.

Table 2. Physical model of the roadway.

\begin{tabular}{|c|c|c|c|c|c|c|}
\hline \multirow[b]{2}{*}{ Test } & \multirow[b]{2}{*}{$\begin{array}{c}\text { Length of } \\
\text { Excavation } \\
\text { Roadway/m }\end{array}$} & \multicolumn{4}{|c|}{ Model Size } & \multirow[b]{2}{*}{$\begin{array}{l}\text { Number of } \\
\text { Grids }\end{array}$} \\
\hline & & $\begin{array}{c}\text { Excavation Roadway } \\
\text { Length } \times \text { Width } \times \\
\text { Height } / \mathrm{m}\end{array}$ & $\begin{array}{c}\text { Air Duct } \\
\text { Length } \times \text { Radium } / \mathrm{m}\end{array}$ & $\begin{array}{c}\text { Connecting } \\
\text { Roadway } \\
\text { Length } \times \text { Width } \times \\
\text { Height } / \mathrm{m}\end{array}$ & $\begin{array}{c}\text { Intake and } \\
\text { Return Airway } \\
\text { Length } \times \text { Width } \\
\times \text { Height } / \mathrm{m}\end{array}$ & \\
\hline L1, L2, L3 & 200 & $200 \times 5 \times 5$ & $200 \times 0.5$ & & & 237,342 \\
\hline L4, L5, L6 & 1000 & $1000 \times 5 \times 5$ & $1000 \times 0.5$ & $45 \times 5 \times 2$ & $500 \times 5 \times 5$ & 463,984 \\
\hline L7, L8, L9 & 2000 & $2000 \times 5 \times 5$ & $2000 \times 0.5$ & & & 764,081 \\
\hline
\end{tabular}

\subsubsection{Mathematical Model}

There are three basic equations of the fluid numerical simulation, which includes the mass conservation equation, the momentum conservation equation, and the energy conservation equation. After the gas outburst accident in the excavation roadway, the airflow should also be satisfied by gas migration. Furthermore, a chemical component exchange exists in this numerical simulation, i.e., $\mathrm{CH}_{4}, \mathrm{O}_{2}$, and $\mathrm{N}_{2}$, so the component transport equation should be introduced.

A turbulent flow is a common flow phenomenon in nature, and the fluid is always in the state of turbulence in most engineering problems. The realizable $k-\varepsilon$ model is adopted because its good performance for solving the adverse pressure gradient and vortex problems.

\subsubsection{Boundary Conditions}

The boundary conditions of the model are shown in Table 3.

From Table 3, the physical model area is the Fluid Type, and the pressure of operation condition is $101.325 \mathrm{kPa}$. The inlet boundary condition includes Inlet 1 of the intake airway, Inlet 2 of the return airway, outburst position, and auxiliary fan. The inlet boundary type of auxiliary fan inlet is the Velocity-inlet, and the other is the Pressure-inlet. The species of the outburst position is $100 \% \mathrm{CH}_{4}$, and the other is $20 \%$ oxygen and $80 \%$ nitrogen. 
The outlet boundary includes Outlet 1 of the intake airway and Outlet 2 of the return airway, the outlet boundary type is also the Pressure-outlet. Furthermore, the species are $20 \%$ oxygen and $80 \%$ nitrogen either.

The gauge pressure of each boundary condition is calculated as follows: Assuming that both the sectional area of the return airway and excavation roadway is $25 \mathrm{~m}^{2}$, the friction resistance coefficient is $100 \times 10^{-4}$, the inlet air quantity of the intake airway and return airway $Q_{10}=Q_{20}$ is $75 \mathrm{~m}^{3} / \mathrm{s}$, and the air quantity of the auxiliary fan $Q_{f a n}$ is $4 \mathrm{~m}^{3} / \mathrm{s}$, $10 \mathrm{~m}^{3} / \mathrm{s}$, and $20 \mathrm{~m}^{3} / \mathrm{s}$, respectively. The outlet of the return airway is $Q_{21}=Q_{20}+Q_{f a n}$, $Q_{12}=Q_{10}-Q_{\text {fan }}$.

Table 3. Boundary conditions of each test.

\begin{tabular}{ccccccc}
\hline & \multicolumn{3}{c}{ Inlet Boundary } & \multicolumn{2}{c}{ Outlet Boundary } \\
\cline { 2 - 7 } Test & Inlet 2/Pa & Inlet 1/Pa & $\begin{array}{c}\text { Auxiliary Fan } \\
\text { Inlet/m·s }\end{array}$ & $\begin{array}{c}\text { Outburst } \\
\text { Position/MPa }\end{array}$ & $\begin{array}{c}\text { Outlet } \\
\mathbf{2 / P a}\end{array}$ & $\begin{array}{c}\text { Outlet } \\
\mathbf{1 / P a}\end{array}$ \\
\hline $\mathrm{L}_{1}$ & 37.97 & 537.97 & 5.10 & 0.1 & 0 & 503.84 \\
$\mathrm{~L}_{2}$ & 46.88 & 1046.88 & 25.48 & 0.2 & 0 & 1019.20 \\
$\mathrm{~L}_{3}$ & 41.12 & 1541.12 & 12.74 & 0.3 & 0 & 1509.60 \\
$\mathrm{~L}_{4}$ & 37.97 & 1537.97 & 5.10 & 0.2 & 0 & 1503.84 \\
$\mathrm{~L}_{5}$ & 41.12 & 1041.12 & 12.74 & 0.1 & 0 & 1009.60 \\
$\mathrm{~L}_{6}$ & 46.88 & 546.88 & 25.48 & 0.3 & 0 & 519.20 \\
$\mathrm{~L}_{7}$ & 46.88 & 1546.88 & 25.48 & 0.1 & 0 & 1519.20 \\
$\mathrm{~L}_{8}$ & 41.12 & 541.12 & 12.74 & 0.2 & 0 & 509.60 \\
$\mathrm{~L}_{9}$ & 37.97 & 1037.97 & 5.10 & 0.3 & 0 & 1003.84 \\
\hline
\end{tabular}

The relationship between the air resistance and the friction resistance coefficient of the roadway is

$$
R=\frac{L U \alpha}{S^{3}}
$$

where $R$ represents the air resistance, $\mathrm{kg} / \mathrm{m}^{7} ; L$ represents the length of the roadway, $\mathrm{m} ; U$ represents the perimeter of the roadway section, $\mathrm{m} ; \alpha$ represents coefficient of frictional resistance, $\mathrm{kg} / \mathrm{m}^{3} ; S$ represents the sectional area of the roadway, $\mathrm{m}^{2}$.

From Equation (1), the air resistance value of the return airway is $R_{10}=R_{12}=R_{20}=$ $R_{21}=0.0032 \mathrm{~kg} / \mathrm{m}^{7}$, the excavation roadway from the air duct outlet to the return airway is $R_{31}=0.0256 \mathrm{~kg} / \mathrm{m}^{7}$. The air pressure $H_{10}=16.13 \mathrm{~Pa}, H_{12}=H_{20}=18 \mathrm{~Pa}, H_{21}=19.97 \mathrm{~Pa}$ and the air pressure of the excavation roadway are calculated by the air quantity of the auxiliary fan and the length of the excavation roadway.

Furthermore, the initial gauge total pressure at Inlet 1 is the sum of the pressure difference of the air door and the air pressure of the upper wind side of the intake airway $H_{10}$, and the initial pressure of Outlet 1 is the sum of the pressure difference of air door and $H_{12}$. Suppose the operation pressure is the standard atmospheric pressure $(101.325 \mathrm{kPa})$, the gauge total pressure at Outlet 2 of the return airway is $0 \mathrm{~Pa}$. Then, the air pressure of each inlet and outlet are calculated as shown in Table 3.

\subsubsection{Controlling Parameters of Fluid Dynamics}

(1) Solver

In the Pressure-based type, the absolute velocity formulation and Pressure-velocity coupling algorithm are usually adopted to solve the problem. Furthermore, using the SIMPLE scheme to calculate the mathematical model, it computes the mass conservation and obtains the pressure field by the mutual correction of pressure and velocity.

(2) Convergence accuracy

A reasonable accuracy is an important parameter to ensure the convergence of the model. The convergence residuals are $10^{-6}$ in this model, and the number of iterations is 500 , so the calculation will be finished when the residuals of each variable are less than 
$10^{-6}$ or the iterations reach to 500 steps. Furthermore, the convergence of the calculation results can be dynamically monitored by checking the iterative residual of each variable.

\subsection{Results of Numerical Simulation}

Using Fluent numerical simulation software, the flow field distributions of the outburst gas of the above nine tests are simulated. Figure 5 illustrates the path-line near the air door of each test on the horizontal plane $1 \mathrm{~m}$ away from the floor, which is colored by the velocity magnitude.
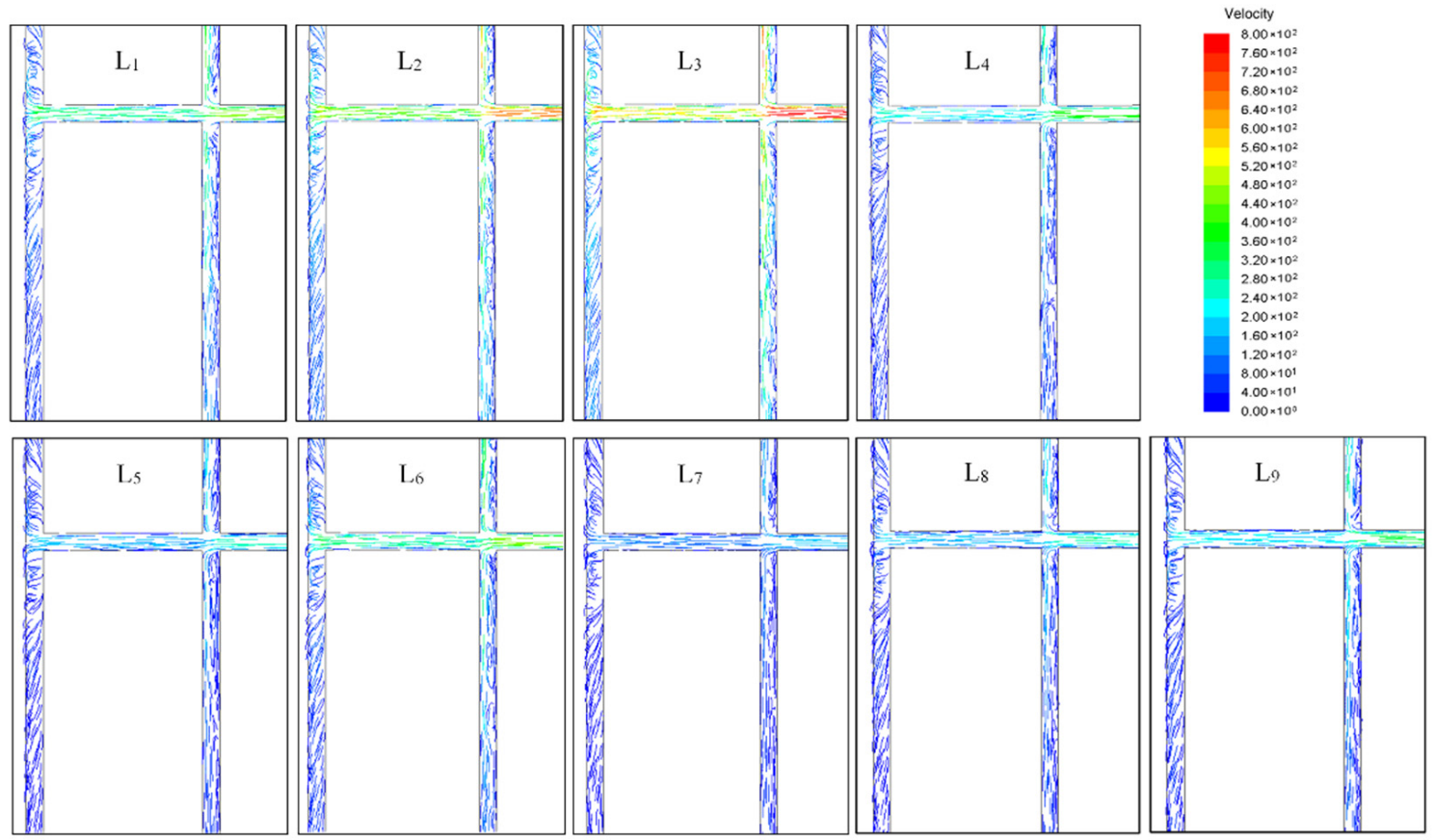

Figure 5. Color map of velocity path-line near the air door.

From Figure 5, the air velocity of $\mathrm{L}_{3}$ is the highest near the air door after the gas burst accident, followed by $L_{2}$ and $L_{1}$, and $L_{7}$ is the smallest. The excavation roadway length of $L_{1}, L_{2}$, and $L_{3}$ is $200 \mathrm{~m}$, which has the greatest air velocity magnitude. The larger air velocity has a greater impact on the ventilation system, especially in the air inlet part. Figures 6 and 7 show the air velocity distributions of the two inlet boundaries.
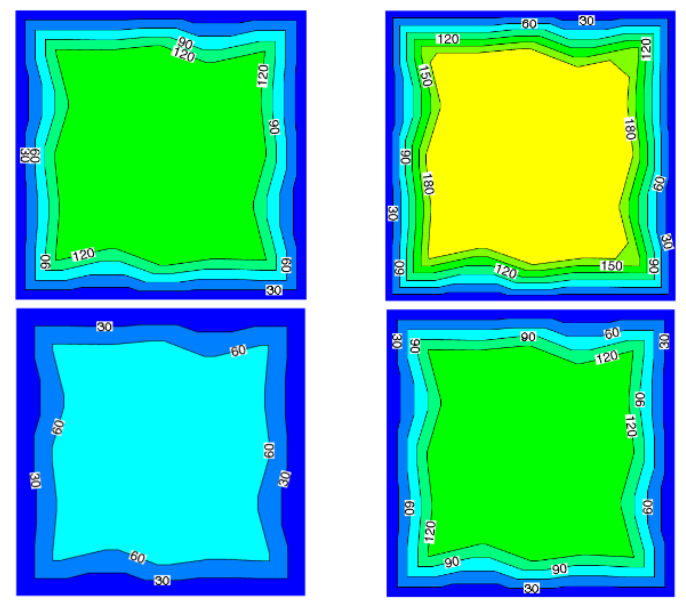
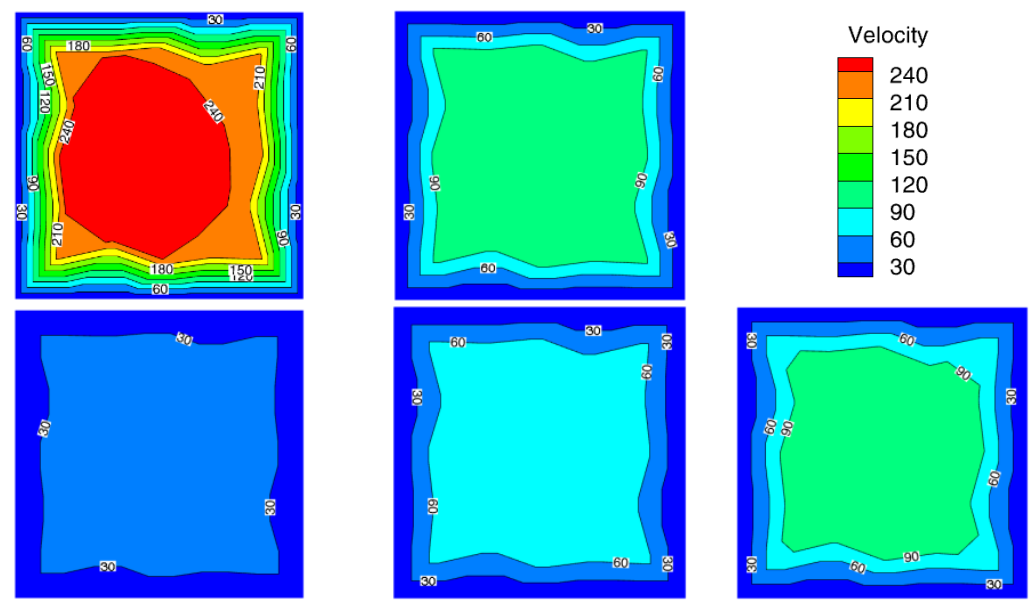

Figure 6. Air velocity of Inlet 2 of the return airway. 

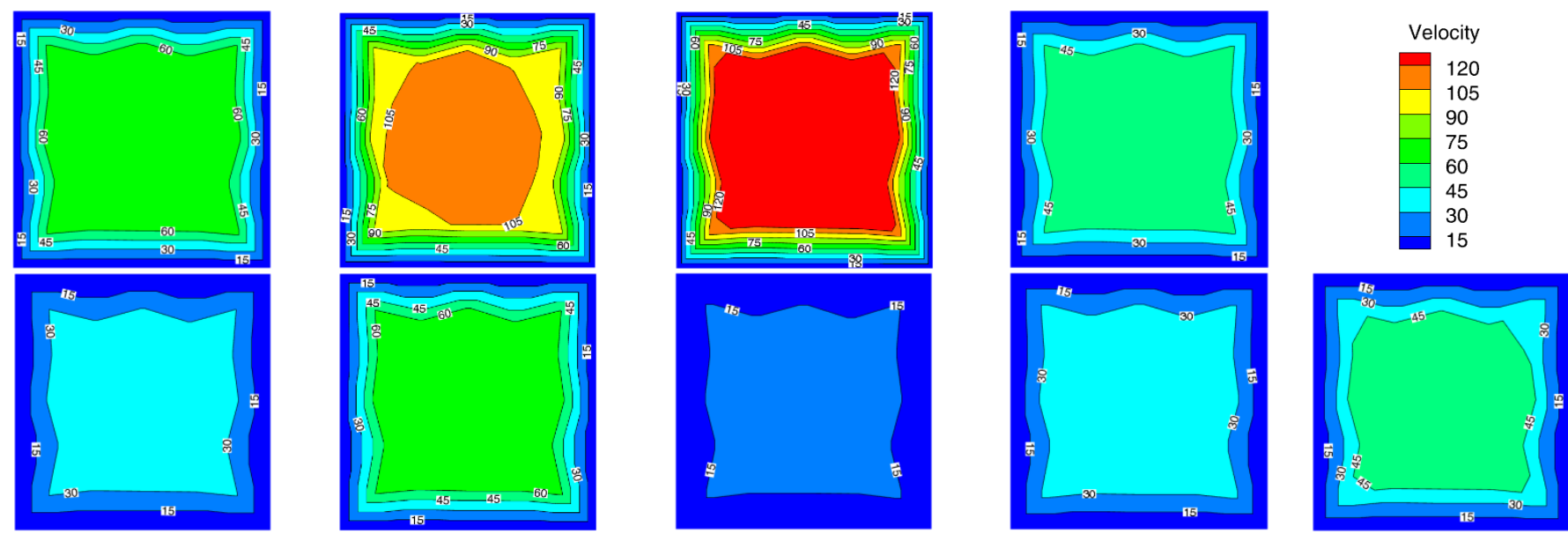

Figure 7. Air velocity of Inlet 1 of the intake airway.

As can be seen from the contour map in Figures 6 and 7, all inlet boundaries are reversed in each test, and the air velocity of Inlet 2 is larger than Inlet 1 . Therefore, the influence of the gas outburst accident on the return air system is greater than that on the inlet air system. Extracting the maximum air velocity of the section, the airflow reversal degree is calculated, as shown in Table 4. Meanwhile, the variation curve of air velocity and airflow reversal degree is shown in Figure 8.

Table 4. Air velocity and airflow reversal degree of the inlet boundary.

\begin{tabular}{ccccc}
\hline \multirow{2}{*}{ Test } & \multicolumn{2}{c}{ Maximum Air Velocity/m·s $\mathbf{s}^{-\mathbf{1}}$} & \multicolumn{2}{c}{ Airflow Reversal Degree } \\
\cline { 2 - 5 } & Inlet 2 & Inlet 1 & Inlet 2 & Inlet 1 \\
\hline $\mathrm{L}_{1}$ & -142.30 & -74.23 & -48.43 & -25.74 \\
$\mathrm{~L}_{2}$ & -206.40 & -111.39 & -69.80 & -38.13 \\
$\mathrm{~L}_{3}$ & -252.70 & -137.31 & -85.23 & -46.77 \\
$\mathrm{~L}_{4}$ & -112.65 & -53.79 & -38.55 & -18.93 \\
$\mathrm{~L}_{5}$ & -78.30 & -34.47 & -27.10 & -12.49 \\
$\mathrm{~L}_{6}$ & -137.58 & -68.94 & -46.86 & -23.98 \\
$\mathrm{~L}_{7}$ & -55.78 & -18.66 & -19.59 & -7.22 \\
$\mathrm{~L}_{8}$ & -80.26 & -38.06 & -27.75 & -13.69 \\
$\mathrm{~L}_{9}$ & -98.28 & -48.59 & -33.76 & -17.20 \\
\hline
\end{tabular}

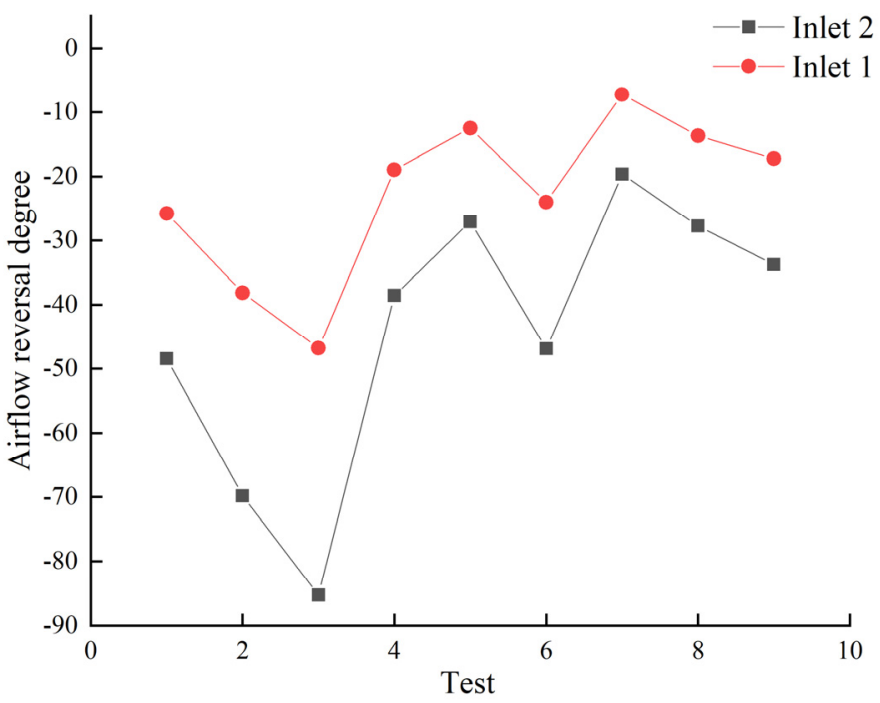

Figure 8. Variation of air velocity and airflow reversal degree. 
From Table 4 and Figure 8, the airflow reversal degree of Inlet 2 is larger than Inlet 1 , that is, because the air pressure distribution of the ventilation system can restrain the outburst gas, and the air pressure variation of the intake airway is smaller than the return airway.

The numerical simulation results show that the airflow reversal degree of $200 \mathrm{~m}$ roadway is greater than that of $1000 \mathrm{~m}$ roadway and $2000 \mathrm{~m}$ roadway. Therefore, the airflow reversal degree decreases with the increase of the roadway length. Furthermore, the outburst air flow pressure of $\mathrm{L}_{3}, \mathrm{~L}_{6}$, and $\mathrm{L}_{9}$ is $0.3 \mathrm{MPa}$, and the absolute value of their airflow reversal degree is greater than the outburst pressure of $0.1 \mathrm{MPa}$ and $0.2 \mathrm{MPa}$ in the same length of the excavation roadway. Therefore, the airflow reversal degree increases with the increase of the outburst pressure and the outburst energy.

\section{Comprehensive Evaluation of Airflow Disorder}

\subsection{Fuzzy Comprehensive Optimization Theory}

According to the main factors that affect the safety and stability of the ventilation system as well as the basic data of orthogonal experiments, the air quantity of the auxiliary fan, the air pressure difference of the air door, and the air flow reversal degree of Inlet 1 and Inlet 2 are used to establish the evaluation model of the airflow disorder on the basis of variable fuzzy theory.

Assuming $\mathrm{F}=\left\{F_{i j}\right\}, i=1, \ldots, m, j=1, \ldots, n$ indicates that the parameter of the $m$ test model corresponds to the set of evaluation factors of $n$. Here, $m=4$. The method of relative membership is adopted to deal with the initial data. There are three situations,

(a) The larger the better

$$
F r_{i j}=\frac{F_{i j}-\min _{1 \leq i \leq m}\left\{F_{i j}\right\}}{\max _{1 \leq i \leq m}\left\{F_{i j}\right\}-\min _{1 \leq i \leq m}\left\{F_{i j}\right\}}
$$

where $F r_{i j}$ is the relative membership of the set $F_{i j}$ and its range is [0,1]; $\max \{\}$ indicates the maximum value of the set; $\min \{\}$ indicates the minimum value of the set.

(b) The smaller the better

$$
F r_{i j}=\frac{\max _{1 \leq i \leq m}\left\{F_{i j}\right\}-F_{i j}}{\max _{1 \leq i \leq m}\left\{F_{i j}\right\}-\min _{1 \leq i \leq m}\left\{F_{i j}\right\}}
$$

(c) The value is equal to 1

$$
F r_{i j}=1,\left(F_{1 j}=F_{2 j}=, \ldots,=F_{m j}\right)
$$

The fuzzy partition matrix is defined as follows,

$$
U=\left[\begin{array}{llll}
u_{11} & u_{12} & \ldots & u_{1 m} \\
u_{21} & u_{22} & \ldots & u_{2 m}
\end{array}\right]=\left[\begin{array}{l}
u_{1 i} \\
u_{2 i}
\end{array}\right]
$$

where $u_{1 i}$ is subordinate to the superior index and $u_{2 i}$ is the inferior index, $\sum_{k=1}^{2} u_{k i}=1$, $u_{k i} \in[0,1]$.

The objective function is the minimal sum of the weight difference squared of the $m$ models.

$$
\min f\left(u_{1 i}\right)=\sum_{i=1}^{m}\left(\left(u_{1 i} \sqrt{\sum_{j=1}^{4}\left[\omega_{j}\left(g r_{j}-F r_{i j}\right)\right]^{2}}\right)^{2}+\left(u_{2 i} \sqrt{\sum_{j=1}^{4}\left[\omega_{j}\left(F r_{i j}-b r_{j}\right)\right]^{2}}\right)^{2}\right)
$$


where $\omega_{j}$ is the weight of each factor; $g r_{j}$ represents the standard superior membership, which is the optimal value of evaluation factor $j ; b r_{j}$ represents the standard inferior subordinate, which is the worst value of evaluation factor $j$.

Supposing $\frac{d f\left(u_{1 i}\right)}{d u_{1 i}}=0$, the optimal fuzzy partition matrix is calculated. Then, the influence of different factors is evaluated by $u_{1 i}$.

\subsection{Quantification and Weight Analysis of the Factors}

\subsubsection{Factors}

The pressure difference of the air door has a strong inhibition of the outburst energy, which belongs to situation (a). The greater the pressure difference of the air door, the greater the pressure energy of the air inlet roadway. The air quantity of the auxiliary fan belongs to situation (a). Because it is opposite to the direction of the outburst gas, the resistance to the migration of the outburst gas increases with the larger air quantity of the auxiliary fan. The airflow reversal degree of Inlet 1 and Inlet 2 also belongs to situation (a), the larger the better.

The above factors consist of the $F$ matrix.

\subsubsection{Weight}

Since the airflow reversal degree is more important than the pressure difference of air door and the air quantity of the auxiliary fan, the weight of the airflow reversal degree is 0.4 and 0.4 , respectively, at Inlet 1 and Inlet 2 . The weight of the pressure difference of the air door is equal to the air quantity of the auxiliary fan, their value is 0.1 , respectively. Then the weight vector $\omega_{j}=(0.1,0.1,0.4,0.4)^{\mathrm{T}}$.

\subsection{Results and Discussion}

The fuzzy comprehensive optimization theory is used to evaluate the airflow disorder degree of the mine ventilation network after a gas outburst accident. From Tables 1 and 4, the $\max \left\{F_{i j}\right\}=(1500,1200,-19.50,-7.22)^{\mathrm{T}}, \min \left\{F_{i j}\right\}=(500,240,-85.23,-46.77)^{\mathrm{T}}$. The membership vector of nine groups is calculated by Equations (2)-(6), $u_{1 i}=(0.4928,2.2160$, $23.5568,0.1586,0.0394,0.3398,0,0.0746,0.1209)$. The values of each factor and evaluation results are shown in Figure 9.

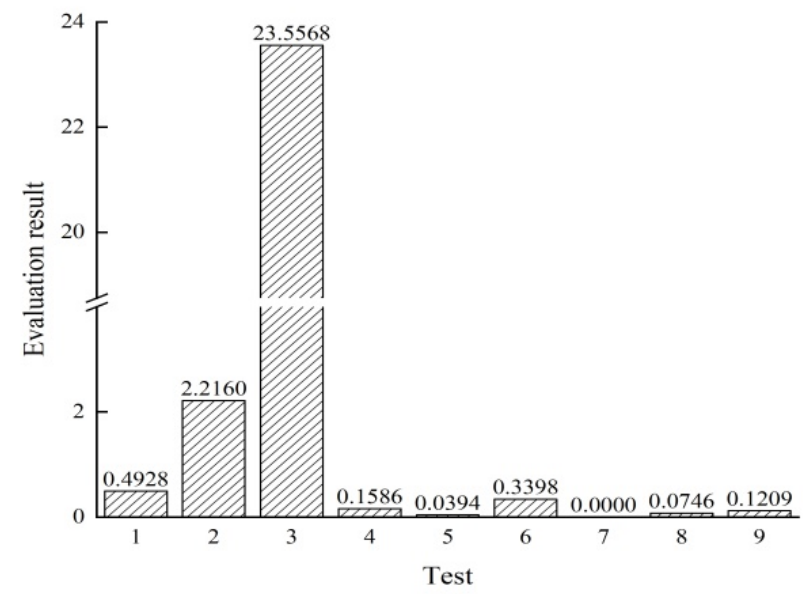

Figure 9. The evaluation results of each test.

From Figure 9, the evaluation result of $\mathrm{L}_{3}$ is the largest, illustrating that this parameter condition has the strongest influence on the ventilation system, and $\mathrm{L}_{7}$ is the smallest. In $\mathrm{L}_{3}$, the length of excavation roadway is $200 \mathrm{~m}$, the outburst pressure is $0.3 \mathrm{MPa}$, the pressure difference of air door is $1500 \mathrm{~Pa}$, and the air quantity of the auxiliary fan is $600 \mathrm{~m}^{3} / \mathrm{min}$. In $L_{7}$, the length of the excavation roadway is $2000 \mathrm{~m}$, the outburst pressure is $0.1 \mathrm{MPa}$, the pressure difference of air door is $1500 \mathrm{~Pa}$, and the air quantity of the auxiliary fan is $1200 \mathrm{~m}^{3} / \mathrm{min}$. 
According to the extreme difference of the range analysis method, the results of the orthogonal experiment are determined. The extreme difference is the difference between the maximum and minimum value of the airflow disorder of each factor. With the increase of the influence range, the disturbance degree of the factor increases. The result is shown in Table 5 and Figure $10 . K_{i}$ represents the sum of levels of factor $i ; k_{i}$ represents the average value of the levels of factor; $R$ represents the polar difference.

Table 5. Range analysis of the orthogonal experiment.

\begin{tabular}{ccccc}
\hline Factors & A & B & C & D \\
\hline$K_{1}$ & 26.27 & 0.53 & 0.91 & 0.77 \\
$K_{2}$ & 0.54 & 2.45 & 2.38 & 23.67 \\
$K_{3}$ & 0.20 & 24.02 & 23.72 & 2.56 \\
$k_{1}$ & 8.76 & 0.18 & 0.30 & 0.26 \\
$k_{2}$ & 0.18 & 0.82 & 0.79 & 7.89 \\
$k_{3}$ & 0.07 & 8.01 & 7.91 & 0.85 \\
$R$ & 8.69 & 7.83 & 7.60 & 7.63 \\
\hline
\end{tabular}

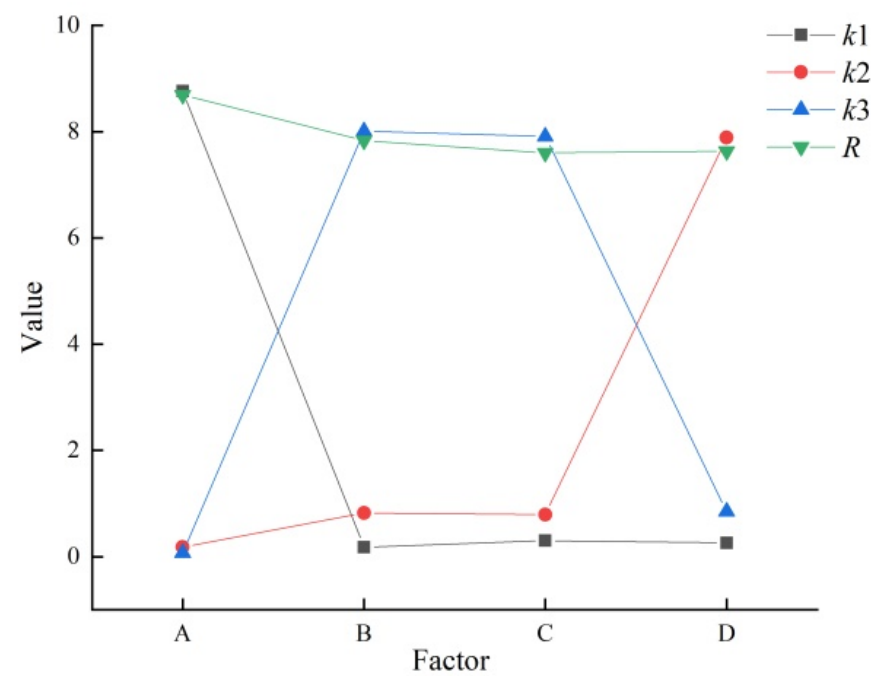

Figure 10. Range analysis of the orthogonal experiment.

From Figure 10, A > B > D > C, the length of the excavation roadway and the outburst pressure are relatively important factors affecting the ventilation system. The airflow reversal degree of the ventilation system increases with the increase of the outburst pressure or the decrease of the length of the excavation roadway.

The energy is continuously attenuated while the outburst gas migrates in the roadway. Adopting the method of reducing the air resistance of the airway or changing the air pressure distribution of the main fans, the initial air pressure in both the roadway and its parallel roadway is easily affected and will be increased in a gas outburst accident. Meanwhile, it will contribute to increase the total air quantity and improve the kinetic energy of the airflow under the condition of the constant capacity of the main fans, so it is harder to reverse the airflow.

\section{Conclusions}

This paper analyzes the reversal principle of airflow induced by a coal and gas outburst in the excavation roadway and proposes the indexes of the airflow disorder. Through an orthogonal experiment, it is found that all the inlet boundaries are reversed in each test, and the air velocity of Inlet 2 is larger than Inlet 1, indicating that the influence of the gas outburst accident on the return air system is greater than that on the inlet air system. Moreover, the larger air velocity has a greater impact on the ventilation system, especially the air inlet part. 
On the basis of the fuzzy comprehensive optimization theory, the evaluation model of the airflow disorder is established. The results show that the order of effect factors for the stability of the mine ventilation system are the length of excavation roadway $>$ outburst pressure $>$ pressure difference of air door $>$ air quantity of auxiliary fan. The most influential result is that the length of the excavation roadway is $200 \mathrm{~m}$, the outburst pressure is $0.3 \mathrm{MPa}$, the pressure difference of the air door is $1500 \mathrm{~Pa}$, and the air quantity of the auxiliary fan is $600 \mathrm{~m}^{3} / \mathrm{min}$. The airflow reversal degree of the ventilation system increases with the increase of the outburst pressure or decreases with the length of the excavation roadway.

Author Contributions: Methodology, J.S.; software, Y.W.; formal analysis, J.C.; investigation, L.L.; resources, J.S., W.H., L.L. and T.L.; data curation, J.S.; writing — original draft preparation, L.L.; writing - review and editing, J.S., J.C. and Z.L.; supervision, J.C. and Y.W.; project administration, J.S.; funding acquisition, J.S. All authors have read and agreed to the published version of the manuscript.

Funding: This work was supported by "the Fundamental Research Funds for the National Natural Science Foundation of China" (51804120, 52074122), "the National Key Research Project of China" (2018YFC08080306), "the Fundamental Research Funds for the Central Universities" (3142018003) and Science and Technology Research Project of Higher Education in Hebei Province (Z2018004).

Acknowledgments: The authors would like to thank the anonymous referees for their thoughtful comments and suggested edits that have improved the rigor and presentation of this work.

Conflicts of Interest: The authors declare that they have no known competing financial interests or personal relationships that could have appeared to influence the work reported in this paper.

\section{References}

1. Zhang, Q.; Yang, C.L.; Li, X.C.; Li, Z.B.; Li, Y. Mechanism and classification of coal and gas outbursts in China. Adv. Civil Eng. 2021, 2021, 5519853. [CrossRef]

2. Dong, G.F.; Liang, Y.P. Analysis of gas emission from outburst coal and formation conditions of countercurrent. Coal Sci. Technol. 2001, 4, 46-48.

3. Kazakov, B.P.; Shalimov, A.V.; Semin, M.A. Stability of natural ventilation mode after main fan stoppage. Int. J. Heat Mass Tran. 2015, 86, 288-293. [CrossRef]

4. Zhou, A.T.; Wang, K. Airflow stabilization in airways induced by gas flows following an outburst. J. Nat. Gas Sci. Eng. 2016, 35, 720-725. [CrossRef]

5. Bascompta, M.; Sanmiquel, L.; Zhang, H. Airflow stability and diagonal mine ventilation system optimization: A case study. J. Min. Sci. 2018, 54, 813-820. [CrossRef]

6. Feng, B.; Zhou, A.T.; Xu, X.H.; Ren, Y.Q. Research on the relationship between coal and gas outburst strength and shock wave overpressure. Min. Eng. Res. 2011, 26, 22-26.

7. Otuonye, F.; Sheng, J. A numerical simulation of gas flow during coal/gas outbursts. Geotech. Geol. Eng. 1994, 12, 15-34. [CrossRef]

8. Zhang, X.X.; Cheng, J.W.; Shi, C.L.; Xu, X.; Borowski, M.; Wang, Y. Numerical simulation studies on effects of explosion impact load on underground mine seal. Min. Metall. Explor. 2020, 37, 665-680. [CrossRef]

9. Yang, C.L.; Li, X.C. Statistical analysis of the causes and rules of especially serious gas and coal dust explosion accident in coal mine. Coal Technol. 2015, 34, 309-311.

10. Cheng, J.W.; Wang, Z.; Li, S.Y.; Song, W.T.; Lu, W.D.; Zhang, Y.J.; Zhao, K. Subsurface strata failure and movement analyses based for improving gas emission control: Model development and application. Energy Sci. Eng. 2020, 8, 3285-3302. [CrossRef]

11. Xue, S.; Zheng, C.S.; Jiang, B.Y.; Zheng, X.L. Effective potential energy associated with coal and gas outburst during underground coal mining: Case studies for mining safety. Arab. J. Geosci. 2021, 14, 1-12. [CrossRef]

12. Hong, L.; Gao, D.M.; Wang, J.R.; Zheng, D. The power source for coal and gas outburst. J. Min. Sci. 2019, 55, 239-246. [CrossRef]

13. Wei, L.J.; Li, S.; Wei, Z.K.; Wang, M.W. Research status and prospect of influence law of coal and gas outburst on ventilation system. Coal Sci. Technol. 2021, 49, 1-7.

14. Ul'yanova, E.V.; Malinnikova, O.N.; Pashichev, B.N.; Malinnikova, E.V. Microstructure of coal before and after gas-dynamic phenomena. J. Mining Sci. 2019, 55, 701-707. [CrossRef]

15. Li, C.W.; Yang, W.; Wei, S.Y.; Li, T.; Chi, L.L. Experimental study on influence range of disaster gas after coal and gas outburst. J. China Coal Soc. 2014, 39, 478-485.

16. Xu, J.; Cheng, L.; Zhou, B.; Peng, S.J.; Yang, X.B.; Yang, W.J. Physical simulation of coal-gas two-phase flow migration during outburst. Chin. J. Rock Mech. Eng. 2019, 38, 1945-1953.

17. $\mathrm{Wu}, \mathrm{X} . ; \mathrm{Xu}, \mathrm{J}$. Numerical simulation of gas ventilation safety in coal and gas outburst process simulation laboratory. Min. Saf. Environ. Prot. 2010, 37, 5-8, 12. 
18. Feng, Y.F.; Wu, Z.Q.; Zhou, A.T. Flow reversals in bypass branch of ascensionally ventilated roadway after coal and gas outburst. China Coal 2012, 83-87. [CrossRef]

19. Yu, X.P.; Huang, S.J. Research on application of downward ventilation to coal mining face in horizontal seam with coal outburst in potential. Coal Sci. Technol. 2005, 6, 27. [CrossRef]

20. Zhou, A.T.; Wang, K.; Wu, Z.Q. Propagation law of shock waves and gas flow in cross roadway caused by coal and gas outburst J. Min. Sci. Technol. 2014, 24, 23-29. [CrossRef]

21. Zhou, A.T.; Wang, K.; Wu, Z.Q.; Li, S. Research on airflow catastrophic law induced by gas pressure in mine. J. China Univ. Min. Technol. 2014, 43, 1011-1018.

22. Wang, K.; Wu, Z.Q.; Zhou, A.T.; Yu, X.; Shen, S.K. Influence of lateral branch wind resistance on wind reversal induced by gas wind pressure. J. Basic Sci. Eng. 2018, 26, 538-549.

23. Li, Z.X.; Liu, Y.; Yu, J.X.; Jia, J.Z. Coupling movement simulation of outburst gas flow and mine ventilation system. J. Chongqing Univ. 2012, 35, 111-116, 135.

24. Li, Z.X.; Li, L.; Yu, J.X.; Han, G. Simulation study on disaster ventilation system of bidirectional burst source in coal face. J. Nat. Disasters 2013, 22, 185-190.

25. Cheng, W.M.; Wang, G.; Zhou, G.; Chen, L.J. Numerical simulation of blast damper failure after coal and gas outburst. J. Chongqing Univ. 2009, 32, 314-318.

26. Dai, S.H.; Wang, Z.T.; Xu, Y. Static and dynamic analysis of the structural safety of steel blast gates. China Saf. Sci. J. 2017, 27, 74-79.

27. Huang, S.J.; Ma, X.X.; Cai, Y. Calculation of influence of outburst gas on ventilation system. Min. Saf. Environ. Prot. 2000, 2, 16-18.

28. Li, Z.X.; Wang, Y.D.; Gao, G.C. 3D simulation of coal mine disaster ventilation based on active wind network. China Saf. Sci. J. 2015, 25, 43-49.

29. Wang, K.; Jiang, S.G.; Zhang, W.Q. Destruction mechanism of gas explosion to ventilation facilities and automatic recovery technology. J. Min. Sci. Technol. 2012, 22, 417-422. [CrossRef]

30. Wu, X.; Cheng, W.Y.; Miu, Y. Research on establishing the indexes system of controlling the coal and gas outburst accident. Procedia Eng. 2011, 26, 2018-2026.

31. Zhang, C.L.; Wang, E.Y.; Xu, J.; Peng, S.J. A new method for coal and gas outburst prediction and prevention based on the fragmentation of ejected coal. Fuel 2021, 287, 119493. [CrossRef]

32. Zhai, C.; Xiang, X.W.; Xu, J.Z.; Wu, S.L. The characteristics and main influencing factors affecting coal and gas outbursts in Chinese Pingdingshan mining region. Nat. Hazards 2016, 82, 507-530. [CrossRef]

33. Yin, S.Y.; Wu, S.P.; Liu, M.B.; You, Z.L. Study on influencing factors of unconfined penetration test based on orthogonal design. Arab. J. Geosci. 2021, 14, 124. [CrossRef] 